\title{
FITOTOXICIDADE DO ALUMÍNIO: EFEITOS, MECANISMO DE TOLERÂNCIA E SEU CONTROLE GENÉTICO
}

\author{
ALUMINUM PHYTOTOXICITY: EFFECTS, TOLERANCE MECHANISMS \\ AND ITS GENETIC CONTROL
}

\author{
Cinara Lima Echart ${ }^{1}$ Suzana Cavalli-Molina ${ }^{2}$
}

- REVISÃO BIBLIOGRÁFICA -

RESUMO

Solos ácidos associados a metais tóxicos são uma das maiores restrições à produção agrícola e, entre os metais, o alumínio destaca-se como um dos maiores problemas em solos com $\mathrm{pH} \leq 5,0$. $O$ melhoramento para tolerância ao alumínio é considerado um excelente caminho para aumentar o desempenho de plantas economicamente importantes cultivadas em solos ácidos ricos nesse metal, como os que ocorrem no sul do Brasil. Para isso, é necessário identificar, entre os diferentes cultivares, aqueles que apresentam mecanismos de tolerância, compreender como esses cultivares agem em sua presenca, bem como conhecer o controle genético da tolerância ao alumínio. Este trabalho apresenta uma revisão sobre o assunto, abordando as formas de alumínio presentes no solo, seu efeito sobre as plantas, os mecanismos de tolerância e o controle genético desta tolerância em diferentes grupos de cereais.

Palavras-chave: tolerância ao alumínio, solos ácidos, cereais.

\section{SUMMARY}

Acid soils and associated mineral toxicity are a great restriction for crop production, and among the metals, aluminum is considered one of the most important problems in soils with $p H \leq 5.0$. Breeding for aluminum tolerance is considered a useful way to improve important economic plants' performance in acid soils with high concentration of this metal, as those which occur in South Brazil. However, for this, it is necessary to identify aluminum-tolerant genotypes, to understand aluminum phytotoxicity and tolerance mechanisms, and to know genetic control of this tolerance. This paper presents a review of these subjects, with emphasis on aluminum forms present in soils, their effect over the plants, the stage of knowledge on aluminum tolerance mechanisms and their genetic control in different cereal groups.
Key words: aluminum tolerance, acid soils, cereals.

\section{INTRODUÇÃO}

A toxicidade ao alumínio é considerada um dos mais importantes problemas de toxicidade de metais em solos ácidos com $\mathrm{pH} \leq 5,0$ (FOY et al., 1978; ANIOL, 1990; BENNET \& BREEN, 1991), por representar um fator limitante de crescimento para as plantas (FOY \& FLEMING, 1976). Desde que, praticamente, a metade dos solos aráveis não irrigados no mundo são ácidos, a toxicidade ao alumínio representa um sério problema para a produção agrícola (MOUSTAKAS et al., 1993).

Em solos tropicais e subtropicais úmidos, com altas precipitações pluviométricas, nutrientes solúveis como cálcio, magnésio, potássio e outros elementos básicos são lixiviados. Quando a remoção de cátions básicos é maior que sua taxa de liberação pelas intempéries, o pH do solo diminui. A mineralização da matéria orgânica por microorganismos do solo resulta na liberação de nitrato e hidrogênio, ocasionando a diminuição do pH. Em pH baixo, o hidrogênio $\left(\mathrm{H}^{+}\right)$atua sobre os minerais liberando íons alumínio $\left(\mathrm{Al}^{3+}\right)$ que ficam predominantemente retidos pelas cargas negativas das partículas de argila do solo, em equilíbrio com o $\mathrm{Al}^{3+}$ em solução. Assim, a quantidade de $\mathrm{Al}^{+3} \mathrm{em}$ solução aumenta com a acidez do solo (BOHNEN, 1995).

\footnotetext{
${ }^{1}$ Biólogo, E-mail ciechart@if1.if.ufrgs.br. Autor para correspondência.

${ }^{2}$ Biólogo, Doutor, Professor Adjunto, Departamento de Genética, Universidade Federal do Rio Grande do Sul, CP 15053, 91501-970, Porto Alegre-RS. Autor para correspondência. E-mail: suzana.molina@ufrgs.br
} 
$\mathrm{O} \mathrm{Al}^{3+}$, por sua vez, é um dos componentes mais importantes da acidez potencial do solo porque reage com a água, liberando íons $\mathrm{H}^{+}$. A acidez potencial devido ao Al trocável é observada em $\mathrm{pH} \leq 5,5$. Em solos com $\mathrm{pH}$ acima de 5,5, o Al encontra-se em formas precipitadas (JONES, 1979; BOHNEN, 1995).

O processo natural de acidificação do solo é muitas vezes intensificado por práticas agrícolas, pela mineração e por práticas de descarte de resíduos (FOY et al., 1978; RAO et al., 1993). No que se refere aos efeitos da agricultura, pode-se salientar que todos resíduos de plantas orgânicas, fertilizantes a base de nitrogênio-fósforo-potássio e materiais nitrogenados são fontes de acidez (JONES, 1979; BOHNEN, 1995).

Problemas de acidificação do solo podem ser corrigidos por calagem, num processo que neutraliza os íons $\mathrm{H}^{+}$e $\mathrm{Al}^{3+}$. Entretanto, a aplicação de calcário na superfície do solo não soluciona os problemas de acidez nas camadas inferiores e a calagem a grandes profundidades geralmente não é possível por apresentar problemas técnicos e econômicos. Por estas razões, o uso de cultivares tolerantes ao $\mathrm{Al}$ torna-se a estratégia mais efetiva para a produção de culturas economicamente importantes em solos ácidos (FOY, 1984).

A alta acidez dos solos do Sul do Brasil, associada a uma grande concentração de alumínio, representa um sério problema para a adaptação de diferentes cereais. Por ser um problema regional, este assunto não tem merecido a atenção destacada de pesquisadores do hemisfério norte. A correção do solo por calagem vem sendo realizada, e têm auxiliado bastante na redução dos efeitos deletérios do Al. Entretanto, para algumas culturas, como é o caso da cevada, anos em que ocorre redução da precipitação pluviométrica, especialmente no período da granação e imediatamente anterior, a impossibilidade das plantas de ultrapassarem a relativamente fina camada do solo em busca de água tem causado acentuadas quebras de safra. Por esse motivo, os efeitos da toxidez do $\mathrm{Al}$, o estabelecimento de metodologias adequadas para a avaliação de genótipos tolerantes e o controle genético da tolerância a este metal têm sido amplamente estudados em plantas de interesse agronômico para o Sul do Brasil, na tentativa de se obter cultivares tolerantes a esse metal (PRIOLI $\boldsymbol{e} t$ al., 1985; CAMBRAIA \& CAMBRAIA, 1995; DORNELLES et al., 1996, 1997).

\section{O ALUMÍNIO NO SOLO E SUA TOXICIDADE NAS PLANTAS}

O Al é o metal mais abundante da crosta da terra, compreendendo aproximadamente $7,5 \%$ de seu peso (HANG, 1984). O Al ocorre em diferentes formas no solo e parte da dificuldade em estudar os processos que ocorrem nas plantas, decorrentes da ação deste metal, pode ser atribuída à complexa química do mesmo. O Al se hidrolisa em solução, de tal modo que a espécie de $\mathrm{Al}$ trivalente, $\mathrm{Al}^{3+}$, predomina em condições ácidas $(\mathrm{pH}<5,0)$, enquanto que as espécies $\mathrm{Al}(\mathrm{OH})^{2+}$ e $\mathrm{Al}(\mathrm{OH})_{2}{ }^{+}$são formadas quando o $\mathrm{pH}$ aumenta. Em $\mathrm{pH}$ próximos da neutralidade ocorre a fase sólida $\mathrm{Al}(\mathrm{OH})_{3}$ e o $\mathrm{Al}(\mathrm{OH})_{4}$ predomina em condições alcalinas. Muitos destes cátions de $\mathrm{Al}$ monoméricos ligam-se a ligantes orgânicos e inorgânicos como $\mathrm{PO}_{4}{ }^{3-}, \mathrm{SO}_{4}{ }^{2-}, \mathrm{F}^{-}$, ácidos orgânicos, proteínas e lipídios (DELHAIZE \& RYAN, 1995). Uma espécie de alumínio polinuclear, $\mathrm{Al}_{13}$, pode também se formar quando soluções de Al são parcialmente neutralizadas com uma base forte (PARKER \& BERTSCH, 1992), mas sua ocorrência natural é ainda desconhecida (DELHAIZE \& RYAN, 1995).

Em decorrência desta complexidade química, a fitotoxicidade dos diferentes tipos de $\mathrm{Al}$ não está totalmente esclarecida. Entre as espécies de $\mathrm{Al}$ mononucleares, complexos de $\mathrm{Al}$ com $\mathrm{SO}_{4}{ }^{2-}$ (KINRAIDE \& PARKER, 1987), $\mathrm{F}^{-}$(WRIGHT, 1989) e ligantes orgânicos (HUE $\boldsymbol{e t}$ al., 1986) são considerados não-tóxicos ou com baixa toxicidade. A rizotoxicidade das espécies mononucleares de hidróxidos de $\mathrm{Al}$ não está clara. $\mathrm{O} \mathrm{Al}^{3+}$ é comprovadamente tóxico, assim como outros policátions (KINRAIDE, 1991).

Muitos estudos têm mostrado que a inibição do crescimento da raiz é o sintoma visível mais rápido da toxicidade do $\mathrm{Al}$ em plantas, o que resulta na redução e em danos do sistema radicular, podendo conduzir à deficiência mineral e estresse hídrico (DEGENHARDT $\boldsymbol{e t} \boldsymbol{a l}$., 1998). A redução do crescimento da parte aérea ocorre num momento posterior (RYAN et al., 1993; JONES \& KOCHIAN, 1995) e parece ser uma conseqüência dos danos que ocorrem na raiz (MATSUMOTO et al., 1976).

Para melhor entender os princípios dos mecanismos de tolerância e sensibilidade ao Al, seus efeitos sobre a inibição do crescimento da raiz e outros sintomas conseqüentes é necessário elucidar onde o $\mathrm{Al}$ age e, principalmente, conhecer qual o efeito primário do $\mathrm{Al}$ responsável pelas modificações morfológicas e fisiológicas que ocorrem.

Está bem documentado que o $\mathrm{Al}$, por ser um ligante metálico com preferência por doadores de oxigênio e alta afinidade por grupos carboxila e fosfato, se liga principalmente aos componentes da parede celular (ZHANG \& TAYLOR, 1991). Entretanto, também há evidências que o mesmo é transportado através da membrana plasmática da raiz

Ciência Rural, v. 31, n. 3, 2001. 
para dentro das células após uma curta exposição do tecido ao Al (LAZOF et al., 1994).

Para alguns autores, a causa primária da inibição do crescimento da raiz pelo $\mathrm{Al}$ é a inibição da mitose nas células do meristema apical da raiz. Já foi mostrado que o $\mathrm{Al}$ pode interagir com os ácidos nucléicos e esse metal tem realmente sido detectado nos núcleos das células das raízes (MATSUMOTO et al., 1976). Inibição da mitose nas células do meristema apical da raiz também já foi mostrada (CLARKSON, 1965; MORIMURA et al., 1978). O que não está totalmente resolvido é o papel do decréscimo da divisão celular como o mecanismo primário da inibição do crescimento da raiz induzida pelo Al. O argumento mais convincente contra a hipótese da inibição da divisão mitótica ser o efeito primário da toxicidade do $\mathrm{Al}$ é o fato do mesmo poder se ligar a muitos componentes celulares antes de entrar no núcleo, e este é, provavelmente, tóxico antes mesmo de penetrar nas células da raiz (HORST et al., 1991). Além disso, devido ao antagonismo entre o $\mathrm{Al}$ e o $\mathrm{Ca}$, e o potencial do $\mathrm{Al}^{3+} \mathrm{em}$ interagir com qualquer sistema que usa $\mathrm{Mg}^{2+}$ ou qualquer forma de fosfato (MARTIN, 1988), o Al pode inibir um grande leque de processos metabólicos essenciais regulados por Ca (RENGEL, 1992), proteínas regulatórias ligadas a GTP e hexoquinases (MARTIN, 1988) e a divisão celular pode ser posteriormente afetada por tais alterações metabólicas. Outra evidência contra é que a inibição direta da divisão celular por interações entre o $\mathrm{Al}$ com o DNA e o RNA requer altas concentrações da espécie de Al tóxico (TEPPER et al., 1989).

Em concentrações moderadas de Al tóxico, a inibição do crescimento celular é, provavelmente, o evento primário e a inibição da divisão celular é uma resposta aos efeitos sobre o crescimento celular, refletindo regulação interna dos processos de crescimento e desenvolvimento (MARSCHNER, 1991).

O aumento da expansão celular pode ser descrito pela equação de Lockhart modificada (DALE \& SUTCLIFFE, 1986), em que o aumento do volume celular depende da condução hidráulica aparente, da extensibilidade da parede celular, da diferença do potencial de água entre as células e seus arredores, da pressão de turgidez limiar e da pressão de turgidez real. A influência do $\mathrm{Al}$ sobre qualquer um desses parâmetros pode alterar a taxa de crescimento de expansão celular (BARCELÓ \& POSCHENRIEDER, 1990).

Diferentes parâmetros relacionados com o crescimento das células das raízes foram estudados por BARCELÓ et al. (1996) em plantas de milho expostas por $24 \mathrm{~h}$ a diferentes $\mathrm{pHs}$ ou a $50 \mu \mathrm{M}$ de $\mathrm{Al}$.
Os resultados obtidos por esses autores sugeriram que tanto o $\mathrm{pH}$ ácido como o $\mathrm{Al}$ diminuem a elasticidade das raízes de milho. $\mathrm{O} \mathrm{Al}$, mas não o $\mathrm{pH}$ ácido, também diminuiu o potencial de pressão das células das raízes. Mas, o efeito mais importante de ambos foi a severa redução da condutibilidade hidráulica aparente das raízes. Esses primeiros resultados indicam que o $\mathrm{Al}$ afeta severamente os parâmetros de relação de água da raiz.

A influência negativa do $\mathrm{Al}$ sobre a condutibilidade hidráulica das raízes (ZHAO et al., 1987; BARCELÓ et al.,1996) apóia a hipótese que a membrana plasmática é o sítio primário da injúria causada pelo Al. A membrana plasmática é estabilizada por íons $\mathrm{Ca}^{2+}$ que se ligam a proteínas e resíduos de pectina carregados negativamente na parede celular, o que influencia a estrutura da parede. O $\mathrm{Ca}^{2+}$ também pode se acumular na camada aquosa difusa adjacente à superfície da membrana, onde pode se ligar a grupos carregados dos fosfolipídios e proteínas da membrana (KAUSS, 1987). Essas ligações com o $\mathrm{Ca}^{2+}$ determinam a rigidez da membrana, de tal modo que removendo o $\mathrm{Ca}^{2+}$ externo, a integridade da membrana fica comprometida, tornandoa vazada e desfazendo sua função normal (HANSON, 1984). O Al $\mathrm{Al}^{3+}$ pode deslocar o $\mathrm{Ca}^{2+}$ apoplasmático por competição pelos ligantes (RENGEL, 1992) ou por reduzir a diferença de potencial negativa na superfície da membrana (KINRAIDE $\boldsymbol{e t}$ al., 1992).

É admitido que o $\mathrm{Al}$ afete a fluidez da membrana por alterar o ambiente químico dos lipídios da membrana, provavelmente, por formar ligações entre as regiões polares dos fosfolipídios (ZHAO et al., 1987). Tal enrijecimento da membrana levaria, direta ou indiretamente, a uma ampla série de alterações relacionadas à função das enzimas ligadas à membrana e do sistema de transporte de íons. Se a ligação do $\mathrm{Al}^{3+}$ com as cargas negativas da superfície da membrana celular é a causa primária da fitotoxicidade do $\mathrm{Al}$, o dano induzido pelo $\mathrm{Al}$ dependeria tanto da atividade do $\mathrm{Al}^{3+}$ na superfície da membrana como do potencial elétrico da superfície. Essa idéia é apoiada pela observação que a redução da toxicidade do $\mathrm{Al}^{3+}$ pelo $\mathrm{Ca}^{2+}$ pode também ser obtida por outros cátions, incluindo o $\mathrm{H}^{+}$, que reduz a negatividade da superfície (KINRAIDE $\boldsymbol{e t}$ al., 1992).

Outra evidência circunstancial, para a hipótese de que a interação do $\mathrm{Al}^{3+}$ com a membrana plasmática seja o mecanismo primário da toxicidade do $\mathrm{Al}$, é fornecida pelo fato de que um dos mais rápidos eventos da concentração de $\mathrm{Al}$ tóxico é a indução da síntese de calose (WISSEMEIER $\boldsymbol{e t}$ al., 1992). Policátions, poliaminas e $\mathrm{Al}^{3+}$ são promotores

Ciência Rural, v. 31, n. 3, 2001. 
potenciais da síntese de calose. Esses policátions se ligam às cargas negativas da superfície de membrana causando um decréscimo de fluidez. A mudança na fluidez da membrana pode abrir os canais de $\mathrm{Ca}^{2+}$, causando um pequeno aumento na concentração de $\mathrm{Ca}^{2+}$ citoplasmático, o que pode ativar a síntese de calose (KAUSS, 1990).

Em 1997, RYAN et al. avaliaram a hipótese do deslocamento do $\mathrm{Ca}^{2+}$ ser a causa da toxicidade do $\mathrm{Al}$, usando linhas isogênicas de trigo que diferiam na tolerância ao $\mathrm{Al}$ em apenas um loco. Os autores mediram tanto o crescimento da raiz como o acúmulo total (apoplasmático mais simplasmático) de ${ }^{45} \mathrm{Ca}^{2+}$ e $\mathrm{Al}^{3+}$ dentro das raízes que tinham sido expostas ao $\mathrm{Al}^{3+}$ sozinho ou ao $\mathrm{Al}^{3+}$ junto com outros cátions. Os autores mostraram que o acúmulo total de $\mathrm{Al}^{3+}$ no ápice das raízes é maior nos genótipos sensíveis ao $\mathrm{Al}$ do que nos tolerantes e sugeriram que o aumento da tolerância ao $\mathrm{Al}$ é causado pela redução de acúmulo de $\mathrm{Al}^{3+}$. Os autores também mostraram que o crescimento da raiz nas linhas sensíveis ao $\mathrm{Al}$ foi severamente inibido por baixas atividades de $\mathrm{Al}^{3+}$, embora $\mathrm{O}$ acúmulo de $\mathrm{Ca}^{2+}$ não tenha sido praticamente afetado. Em soluções contendo a mesma atividade de íons $\mathrm{Al}^{3+} \mathrm{e} \mathrm{Ca}^{2+}$ do experimento anterior, mas que também incluíam íons $\mathrm{Mg}^{2+}, \mathrm{Sr}^{2+}$ ou $\mathrm{Na}^{+}$, o crescimento melhorou, enquanto o acúmulo de ${ }^{45} \mathrm{Ca}^{2+}$ foi significantemente diminuído. Desde que a maioria do ${ }^{45} \mathrm{Ca}^{2+}$, acumulado pelas raízes durante os tratamentos de curta duração, fica no apoplasto, estes resultados indicam que o deslocamento do $\mathrm{Ca}^{2+}$ do apoplasto pelo $\mathrm{Al}$ não pode explicar a inibição do crescimento da raiz induzida pelo $\mathrm{Al}$ e, portanto, não apóia a hipótese de deslocamento do $\mathrm{Ca}^{2+}$ para explicar a toxicidade do Al.

Outra hipótese envolvendo interações entre o $\mathrm{Al}$ e o $\mathrm{Ca}$, formulada para explicar o mecanismo de toxicidade do $\mathrm{Al}^{3+}$, refere-se ao transporte de $\mathrm{Ca}^{2+}$. O transporte de $\mathrm{Ca}^{2+}$ para dentro das células é energeticamente passivo e é, provavelmente, mediado por canais de membrana. Muitos cátions polivalentes inibem este transporte de $\mathrm{Ca}^{2+} \mathrm{e}$ a habilidade do $\mathrm{Al}^{3+}$ em reduzir a entrada e o transporte de $\mathrm{Ca}^{2+}$, nas plantas, está bem documentado (HUANG et al., 1992; RENGEL, 1992), podendo inclusive causar deficiência desse composto (FOY, 1984). Além disso, foi verificado que a inibição da entrada de $\mathrm{Ca}^{2+}$, induzida pelo $\mathrm{Al}^{3+}$, é mais afetada em cultivares de trigo sensíveis ao $\mathrm{Al}$ do que naquelas tolerantes (HUANG et al., 1992; RYAN \& KOCHIAN, 1993). Essas observações sugerem que a inibição do crescimento da raiz induzida pelo $\mathrm{Al}$ possa ser causada pela inibição do transporte de $\mathrm{Ca}^{2+}$. Entretanto, em 1994, RYAN et al. mostraram que baixas con- centrações de $\mathrm{Al}^{3+}$ podiam inibir o crescimento da raiz sem inibir a entrada de $\mathrm{Ca}^{2+}$ e que a adição de outros cátions, como $\mathrm{Na}^{+}$e $\mathrm{Mg}^{2+}$, a um tratamento com $\mathrm{Al}^{3+}$, melhorava o crescimento das raízes e, ao mesmo tempo, inibia a entrada de $\mathrm{Ca}^{2+}$. O reverso seria esperado se a toxicidade ao $\mathrm{Al}$ fosse causada pela inibição do transporte de $\mathrm{Ca}^{2+}$. Portanto, embora alguma concentração de $\mathrm{Al}^{3+}$ reduza a entrada de $\mathrm{Ca}^{2+}$ nas células e talvez contribua para o estresse causado pelo $\mathrm{Al}$ no processo, a inibição do crescimento da raiz por baixas concentrações de $\mathrm{Al}$ parece ser causado por outras interações.

Os resultados obtidos até o presente não esclarecem totalmente o mecanismo de fitotoxicidade do $\mathrm{Al}$, mas também não excluem a possibilidade que a ligação do $\mathrm{Al}$ à superfície da membrana plasmática possa ser o mecanismo primário da toxicida$\mathrm{de}$, nem que interações alternativas entre $\mathrm{Al}^{3+} \mathrm{e} \mathrm{Ca}^{2+}$ ou uma interrupção da homeostase do $\mathrm{Ca}$, induzida pelo $\mathrm{Al}$, desempenhem um papel importante nos eventos iniciais que levam à inibição do crescimento da raiz induzida pelo Al. Esta revisão mostra que investigações sobre a fitotoxicidade do $\mathrm{Al}$ e os mecanismos de tolerância são extremamente complexos e necessitam mais estudos.

Seja qual for a causa primária da toxicidade do $\mathrm{Al}$, as anomalias e os danos causados ao sistema radicular ocasionam a exploração de um menor volume de solo pelas plantas, resultando não só em deficiências na absorção de nutrientes, bem como na deficiência do aproveitamento da água do solo, o que pode ser mais nocivo. Assim, restringindo a expansão das raízes em até $15-20 \mathrm{~cm}$ de solo, a toxicidade do $\mathrm{Al}$ torna-se responsável pela maior susceptibilidade à deficiência de água, o que fica mais grave nos períodos de estiagem durante o ciclo vegetativo das plantas (OLMOS \& CAMARGO, 1975)

\section{TOLERÂNCIA AO ALUMÍNIO}

Espécies e cultivares de plantas variam extensivamente no grau de tolerância ao excesso de Al no meio em que crescem. BENNET \& BREEN (1991) comentam que o alumínio possui algumas propriedades inerentes distintas de elementos biologicamente importantes, como o $\mathrm{Ca}$, e essas propriedades são fundamentais para as plantas desenvolverem mecanismos de tolerância ao Al.

Duas categorias de mecanismo de tolerância ao Al têm sido propostas. A primeira envolve mecanismos de tolerância a altas concentrações de Al no simplasto da raiz e pode estar relacionada a diferentes mecanismos como quelação do $\mathrm{Al}$ no citosol, compartimentação do Al nos vacúolos, liga-

Ciência Rural, v. 31, n. 3, 2001. 
ções alumínio-proteínas, evolução de enzimas tolerantes ao $\mathrm{Al}$ (TAYLOR, 1988). Entretanto, pouco se sabe sobre esse mecanismo de tolerância. TICE $\boldsymbol{e t}$ al. (1992) não conseguiram detectar $\mathrm{Al}$ em vacúolos da extremidade da raiz, nem em cultivares tolerantes, nem em cultivares sensíveis de trigo, quando as mesmas foram expostas por 48 horas ao $\mathrm{Al}$, utilizando coloração com morin. Diferentemente, BARCELÓ et al. (1996) detectaram Al, através de microanálises de raio-X, em depósitos densos de elétrons em vacúolos da ponta de raízes pequenas de plântulas de milho tratadas com $\mathrm{Al}^{3+}$ por 24 a $120 \mathrm{~h}$. Esses autores encontraram $\mathrm{Al}$ associado a altas concentrações de $\mathrm{P}$, mas não encontraram diferenças entre cultivares, de modo que não puderam estabelecer uma relação entre a concentração de $\mathrm{Al}$ nos vacúolos e o índice de tolerância baseado no crescimento da raiz.

A segunda categoria de mecanismo de tolerância ao Al está relacionada com a habilidade de excluir o Al do ápice da raiz, e pode envolver diferentes tipos de mecanismos como imobilização do Al nas paredes celulares, permeabilidade seletiva do Al na membrana plasmática, formação de uma barreira de $\mathrm{pH}$ induzida pela planta na rizosfera ou no apoplasto da raiz, eliminação de ligantes quelados (TAYLOR, 1988). Estudos com cultivares de trigo e milho mostraram que cultivares tolerantes ao Al contêm concentrações de Al menores que os cultivares sensíveis (TICE $\boldsymbol{e t} \boldsymbol{a l}$., 1992; DELHAIZE et al., 1993a; LLUGANY et al., 1994). Embora ainda não existam técnicas que permitam uma definição clara se o Al está no simplasto ou no apoplasto, técnicas de fracionamento ou de coloração fluorescente com morin têm permitido mostrar que cultivares de trigo tolerantes ao $\mathrm{Al}$ acumulam menos $\mathrm{Al}^{3+}$ no apoplasto que os cultivares sensíveis, enquanto a concentração de $\mathrm{Al}^{3+}$ no simplasto, associada com uma inibição de $50 \%$ do crescimento da raiz, foi similar em cultivares tolerantes e sensíveis (TICE $\boldsymbol{e t} \boldsymbol{a l} ., 1992$ ). Esses resultados apóiam a hipótese de que a exclusão do $\mathrm{Al}$ da extremidade das raizes é um mecanismo importante para evitar a toxicidade do $\mathrm{Al}$, enquanto a desintoxicação do citoplasma não parece desempenhar um papel essencial.

A exclusão de $\mathrm{Al}$ da extremidade das raízes pode ser obtida pela eliminação de ácidos orgânicos da ponta da raiz. Está bem estabelecida a habilidade dos ácidos orgânicos de quelarem e eliminar Al não-fitotóxico, e tem sido especulado que plantas tolerantes ao $\mathrm{Al}$ usam ácidos orgânicos para se desintoxicarem do $\mathrm{Al}^{3+}$ tanto internamente como na rizosfera. MIYASAKA et al. (1991) forneceram evidências que o mecanismo de tolerância ao Al, em feijão, envolve efluxo de ácido cítrico. DELHAIZE et al. (1993a, 1993b) demostraram que, em linhas isogênicas de trigo, a presença de $\mathrm{Al}$ induz a liberação de maior quantidade de malato do ápice da raiz nos genótipos tolerantes ao $\mathrm{Al}$ quando comparados com plantas de genótipos sensíveis. Os autores sugeriram que o aumento da secreção de malato protege a planta por quelação e desintoxicação. Posteriormente, esta correlação entre a liberação de malato e a tolerância ao $\mathrm{Al}$ foi encontrada em vários outros cultivares de trigo (RYAN $\boldsymbol{e}$ t al., 1995) e em milho (PELLET et al., 1994).

FOY et al. (1965) propuseram um mecanismo de exclusão de $\mathrm{Al}$ que envolve o aumento do $\mathrm{pH}$ da rizosfera, reduzindo a concentração de $\mathrm{Al}^{3+}$ em favor de espécies de $\mathrm{Al}$ menos tóxicas, como os hidróxidos de $\mathrm{Al}$ e os fosfatos de Al (MARTELL \& MOTEKAITIS, 1989). Posteriormente, outros trabalhos foram realizados relatando a existência de correlação entre a tolerância ao $\mathrm{Al}$ e o aumento transiente do $\mathrm{pH}$ da solução de crescimento em várias espécies (FOY et al., 1967; MUGWIRA et al., 1978; FLEMING, 1983; DODGE \& HIATT, 1992), mas ainda não foram feitas demonstrações diretas desse mecanismo de tolerância. Na maioria dessas pesquisas, não ficou claro se as diferenças de $\mathrm{pH}$ eram a causa da tolerância ao $\mathrm{Al}$ ou se elas eram o resultado da inibição do crescimento da raiz induzida pelo $\mathrm{Al}$ nos cultivares sensíveis. TAYLOR (1991) comenta dois problemas inerentes aos estudos baseados na medida do $\mathrm{pH}$ da solução de crescimento. O primeiro refere-se à origem do nitrogênio na solução de crescimento que pode ter um significante impacto no $\mathrm{pH}$ da rizosfera, uma vez que o nitrato $\left(\mathrm{NO}_{3}{ }^{-}\right)$conduz à alcalinização do meio, enquanto a amônia $\left(\mathrm{NH}_{4}^{+}\right)$pode causar a acidificação da rizosfera. Portanto, a taxa de $\mathrm{NO}_{3}{ }^{-}$para $\mathrm{NH}_{3}$ no meio de crescimento de cada experimento pode ter um efeito substancial no $\mathrm{pH}$ da solução de crescimento (TAYLOR, 1991). O segundo problema encontrado é que medidas do $\mathrm{pH}$ da solução refletem mudanças de $\mathrm{pH}$ associadas com toda a raiz e não especificamente com a extremidade da mesma, que é o sítio primário da toxicidade do Al. Por essa razão, MIYASAKA et al. (1989) usaram microeletrodos de $\mathrm{pH}$ para mapear o $\mathrm{pH}$ da superfície da raiz de trigo e mostraram que um cultivar de trigo tolerante ao $\mathrm{Al}$ manteve um $\mathrm{pH}$ levemente aumentado no topo da raiz, mas não nas demais partes da raiz, comparado com o cultivar sensível ao Al. Nesses experimentos, não foi determinado se as diferenças no $\mathrm{pH}$ da rizosfera no ápice determinavam a tolerância ao $\mathrm{Al}$, ou se eles meramente refletiam diferenças na função da raiz após o início da toxicidade ao Al no cultivar sensível.

Ciência Rural, v. 31, n. 3, 2001. 
Recentemente, DEGENHARDT $\boldsymbol{e t} \boldsymbol{a l}$. (1998) conduziram um experimento para melhor compreender a toxicidade e tolerância ao Al, utilizando um mutante de Arabidopsis thaliana. Esse mutante, denominado alr-104, é um mutante do cromossomo 4, tolerante ao $\mathrm{Al}$, que não exibe liberação de ácido orgânico pela raiz. Um sistema de microeletrodos foi usado para medir o fluxo de íons $\mathrm{H}^{+}$nas raízes, permitindo uma resolução temporal e espacial muito grande. $\mathrm{Na}$ ausência de $\mathrm{Al}$, não foram detectadas diferenças no fluxo de $\mathrm{H}^{+}$na raiz entre o tipo selvagem e o mutante alr-104. Entretanto, a exposição ao $\mathrm{Al}$ duplicou o influxo de $\mathrm{H}^{+}$na extremidade da raiz do mutante, ocasionando uma elevação do $\mathrm{pH}$ da rizosfera nesta região quando comparado com o tipo selvagem. Ensaios de crescimento da raiz, em solução nutriente com $\mathrm{pH}$ controlado, foram usados para avaliar a tolerância ao $\mathrm{Al}$ do tipo selvagem e do mutante. $\mathrm{O}$ aumento do $\mathrm{pH}$ da solução nutriente de 4,4 para 4,5 levou a um aumento significante da tolerância ao Al no tipo selvagem, o que é consistente com a idéia que o influxo de $\mathrm{H}^{+}$ aumentado pode explicar a maior tolerância ao $\mathrm{Al}$ do mutante alr-104. Diferenças na tolerância ao Al entre o tipo selvagem e o mutante desapareceram quando as raízes foram crescidas em uma solução com pH tamponado, sugerindo que a tolerância ao Al no mutante alr-104 é mediada somente por mudanças no $\mathrm{pH}$ da rizosfera. Esse estudo forneceu a primeira evidência efetiva de um mecanismo de tolerância ao $\mathrm{Al}$ baseado no aumento do $\mathrm{pH}$ da superfície da raiz induzido por $\mathrm{Al}$.

\section{MÉTODOS DE SELEÇÃO PARA TOLERÂNCIA AO ALUMÍNIO}

Como a seleção de plantas tolerantes ao Al tem sido considerada a alternativa mais adequada para aumentar a produção em solos ácidos com altas concentrações de $\mathrm{Al}$, o primeiro passo nesta abordagem é estabelecer um sistema rápido e preciso para a seleção de um grande número de plantas. Diferentes métodos de seleção têm sido empregados: cultura em campo ou em solo sob condições controladas e cultura em soluções nutritivas. Cada uma dessas metodologias tem vantagens e desvantagens distintas. Técnicas de seleção a campo selecionam germoplasmas sob condições climáticas e de solo naturais, e os dados finais refletem uma integração dos efeitos do estresse da toxicidade do $\mathrm{Al}$ e todas as condições do solo com o ciclo de crescimento completo. As desvantagens dos testes a campo são o tempo requerido (usualmente um período de crescimento completo), problemas da variabilidade das características do solo, efeitos de resistência diferencial a doenças e pestes, vulnerabilidade do material às intempéries ambientais como seca ou inundação, e a inabilidade em interpretar o desempenho apresentado pelas plantas em função da complexidade das interações do meio ambiente.

Em experimentos empregando solos sob condições controladas, é difícil selecionar solos que sejam adequados para uso em seleção de plantas tolerantes ao $\mathrm{Al}$ visto que, em solos, a toxicidade ao $\mathrm{Al}$ não é o único fator limitante. Além disso, o efeito primário do $\mathrm{Al}$ nas plantas é a inibição do crescimento da raiz, e as raízes não são facilmente observáveis usando cultura em solo.

Devido às limitações da seleção a campo e em solo sob condições controladas, a maioria dos trabalhos de seleção de cultivares tolerantes ao $\mathrm{Al}$ tem sido conduzida usando metodologias que utilizam solução de nutrientes. Nessa abordagem, diferentes técnicas têm sido empregadas para avaliar a tolerância e a sensibilidade ao $\mathrm{Al}$. O critério mais utilizado para medir a toxicidade ao $\mathrm{Al}$ é a comparação do crescimento e/ou do peso das raízes de plantas crescidas em solução nutriente com $\mathrm{pH}$ ácido e uma concentração adequada de $\mathrm{Al}$ com plantas controles crescidas na ausência de Al. Eventualmente, outras características como número de raízes, coloração e ramificação das mesmas também têm sido utilizadas (PRIOLI et $\boldsymbol{a l}$., 1985; CAMBRAIA \& CAMBRAIA, 1995). Alternativamente, tem sido avaliado o recrescimento da raiz após o tratamento com Al. Nesse caso, as plântulas são colocadas em solução nutritiva sem $\mathrm{Al}$, sendo depois de aproximadamente 48 horas transferidas para solução nutritiva contendo $\mathrm{Al}$ na qual permanecem por mais 48 horas, retornando para a solução inicial por mais 72 horas, quando são então avaliadas quanto ao recrescimento da raiz principal a partir do dano (calose) causado pelo $\mathrm{Al}^{3+}$. A tolerância da planta ao $\mathrm{Al}$ pode ser medida dessa forma, porque nas plântulas sensíveis as raízes primárias não crescem e permanecem engrossadas mostrando no ápice uma injúria típica (LAGOS et al.,1991; DORNELLES et al., 1996, 1997).

Além desses parâmetros de resposta ao $\mathrm{Al}$, têm sido utilizados métodos de coloração da raiz que apresentam a vantagem de serem mais rápidos. Um método utilizando o corante hematoxilina foi desenvolvido baseado na formação do complexo corado entre a hematoxilina e o $\mathrm{Al}$ ligado na raiz (POLLE $\boldsymbol{e t}$ al., 1978). Esse método tem sido utilizado para avaliar tolerância em trigo (TAKAGI $\boldsymbol{e t}$ al., 1981) e em cevada (MINELLA \& SORRELLS, 1997), entre outros. Ainda, coloração com erichrome cyaneine $R$ tem sido utilizada para avaliar o recrescimento da raiz após tratamento com Al (ANIOL,

Ciência Rural, v. 31, n. 3, 2001. 
1995; FENG MA et al., 1997). Nesse método, quando o Al não destrói o meristema apical da raiz, a parte da raiz que cresce após tratamento com $\mathrm{Al}$ permanece branca (não corada), enquanto raízes que foram afetadas pelo Al ficam densamente coradas (cor de rosa).

\section{CONTROLE GENÉTICO DA TOLERÂNCIA AO ALUMÍNIO EM PLANTAS}

Espécies de plantas diferem significativamente na tolerância ao excesso de $\mathrm{Al}$ disponível em solos ácidos ou em soluções nutritivas. Entre os cereais, a espécie mais tolerante é o centeio seguido pela aveia, trigo e cevada (GALLEGO \& BENITO, 1997). KHATIWADA et al. (1996), analisando o crescimento relativo da raiz de 62 cultivares de arroz, verificaram que apenas três foram suscetíveis ao $\mathrm{Al}$, o que indica que a maioria dos cultivares tradicionais desta espécie que crescem em solos ácidos já possuem tolerância à toxicidade do $\mathrm{Al}$.

A tolerância ao Al é geneticamente controlada, podendo ser monogênica ou poligênica conforme a espécie, mas, na maioria dos casos, este assunto não está completamente esclarecido. Em trigo, de acordo com KERRIDGE \& KRONSTADE (1968), um único gene dominante seria responsável pela tolerância ao Al, tendo esse resultado sido concluído a partir de cruzamentos entre as variedades Druchamp e Brevor. Entretanto, ANIOL (1990), estudando linhas ditelossômicas da variedade Chinese Spring, mostrou que a tolerância ao $\mathrm{Al}$ em trigo não é monogênica, mas determinada por vários genes de efeitos aditivos com altos valores de herdabilidade. LAGOS et al. (1991) referem dois genes controlando a tolerância ao $\mathrm{Al}$ em trigo, baseados na análise de cruzamentos da variedade brasileira $\mathrm{BH}$ 1146 com CI14124 e com Atlas 66. Em milho, alguns autores concluíram que a tolerância ao $\mathrm{Al}$ é controlada por um único loco (RHUE et al., 1978; GARCIA \& SILVA, 1979; MOON et al., 1997), enquanto outros autores têm indicado a presença de dois ou mais genes (PRIOLI, 1987; MAGNAVACA et al., 1987). KHATIWADA et al. (1996) mostraram que, no arroz, estão envolvidos vários genes na tolerância ao $\mathrm{Al}$, e que a herança é aditiva com interação alélica de dominância nos diversos locos. Estudos similares, em soja, indicaram um efeito aditivo na absorção de elementos minerais e crescimento da raiz na presença de Al (SPEHAR \& GALWEY, 1996). A análise genética tem mostrado que a tolerância ao $\mathrm{Al}$, no cultivar Dayton de cevada, é determinada por um único gene dominante, com múltiplos alelos e a expressão da tolerância é dependente da interação dos alelos e da concentração de $\mathrm{Al}$ (MINELLA \& SORRELLS, 1997).
Os principais genes que controlam a tolerância ao $\mathrm{Al}$ em trigo estão localizados no braço curto do cromossomo 5 do genoma $\mathrm{A}$ e nos braços longos dos cromossomos 2 e 4 do genoma D (ANIOL \& GUSTAFSON, 1984; ANIOL, 1990; LAGOS et al., 1991). Em milho, SIBOV et al. (1999), fazendo o mapeamento genético e molecular dos cultivares da linha Cat-100-6, identificaram a presença de dois locos responsáveis pela tolerância ao $\mathrm{Al}$, um localizado no braço curto do cromossomo 6 e outro no cromossomo 10. GALLEGO \& BENITO (1997), estudando os cultivares de centeio Ailés, altamente tolerante, e Rioveda, medianamente tolerante ao $\mathrm{Al}$, propuseram a existência de três genes Alt controlando a tolerância ao Al nesta espécie, o que concorda com análises prévias feitas por ANIOL \& GUSTAFSON (1984), que usando linhas de adição e substituição trigo-centeio, haviam localizado três genes de tolerância ao Al nos cromossomos 3, 4 e 6 do genoma $\mathrm{R}$ dessa espécie. ST $\varnothing \mathrm{LEN}$ $\&$ ANDERSEN (1978) encontraram um gene, designado Pht, que controla tolerância a solos com $\mathrm{pH}$ baixo, no loco $\mathrm{K}$ do cromossomo 4 de cevada. O gene que controla a tolerância ao $\mathrm{Al}$ em cevada, denominado Alp, identificado através de estudos com os cultivares Dayton e Smooth 86 (REID, 1969), ainda não foi mapeado, mas parece estar fisicamente associado com o gene Pht no mesmo cromossomo (MINELLA \& SORRELLS, 1997).

Assim, os estudos têm mostrado que os genes envolvidos na tolerância ao $\mathrm{Al}$ estão localizados, preferencialmente, no cromossomo 4 em diferentes espécies de gramíneas. Muitos estudos de mapeamento genético comparativo entre as espécies dessa família mostram a presença de grupos de ligação conservados entre as espécies (AHN $\boldsymbol{e t}$ al., 1993; DEVO et al., 1993; SHERMAN et al., 1995; SAGHAI-MAROOF $\boldsymbol{e t} \boldsymbol{a l}$., 1996). A conservação na estrutura do genoma de espécies de plantas relacionadas pode prover a base para a interpretação da informação genética entre as espécies. Se as relações de ligação são conservadas, a informação genética e os marcadores moleculares identificados em uma espécie podem ser explorados em outras espécies, aumentando o número de marcadores potenciais (SAGHAI-MAROOF et al., 1996). Isso se torna altamente vantajoso na família das gramíneas que contém 10.000 espécies, incluindo grupos economicamente importantes como o arroz, cevada, trigo, centeio e milho. Essa família apresenta todas as características de um modelo ideal para estudos genéticos por incluir excelentes coleções de estoques citogenéticos, extensivos mapas clássicos e moleculares, pequeno tamanho do genoma (arroz e sorgo), técnicas de mutagênese e transposição bem caracte- 
rizadas e vários estudos de transformação (BENNETZEN \& FREELING, 1993). Desse modo, informações definidas como importantes em uma espécie podem ser estudadas em espécies relacionadas e até mesmo extrapoladas para muitos outros grupos, baseadas em comparações genômicas.

\section{CONCLUSÕES}

O alumínio é um dos principais responsáveis pela baixa performance de plantas economicamente importantes em solos ácidos. Das espécies de alumínio, a forma $\mathrm{Al}^{3+}$ é comprovadamente tóxica e o sintoma inicial, e mais nocivo de sua toxicidade, é a inibição do crescimento da raiz. Espécies de plantas variam extensivamente no grau de tolerância ao $\mathrm{Al} \mathrm{e}$ as plantas tolerantes apresentam diferentes mecanismos para sobreviverem à presença desse metal. Os mecanismos de tolerância são extremamente complexos e vários estudos vêm sendo realizados na tentativa de elucidá-los. Até o momento, sabe-se que as plantas podem ser tolerantes por serem capazes de tolerar altos níveis de $\mathrm{Al}$ no simplasto ou por se desintoxicarem do mesmo após sua entrada na célula. Embora um grande volume de conhecimento tenha sido construído nos últimos anos, o entendimento da fisiologia da tolerância em plantas cultivadas é ainda rudimentar. Progressos na definição dos sítios primários da toxicidade do $\mathrm{Al}$ requerem o desenvolvimento de novas técnicas capazes de detectar a entrada do $\mathrm{Al}$ no apoplasto e no simplasto num período relativamente curto. É necessário o desenvolvimento de técnicas que permitam verificar a ocorrência e medir a atividade de canais permeáveis a ácidos orgânicos nas membranas plasmáticas das células da parte apical da raiz. $\mathrm{O} \mathrm{Al}$ provavelmente necessita interagir com algum componente da membrana plasmática para promover o efluxo de ácidos orgânicos, mas, ao mesmo tempo, a membrana precisa ser protegida dos efeitos tóxicos do Al. Estudos para clarificar esse aparente paradoxo são necessários. A tolerância ao $\mathrm{Al}$ é geneticamente controlada e as espécies de plantas diferem significativamente quanto ao grau dessa tolerância. A análise genética em diferentes espécies de cereais mostrou que a tolerância ao $\mathrm{Al}$ pode ser controlada de diferentes formas, desde um único gene dominante até uma forma complexa com genes de efeitos aditivos agindo em diferentes rotas bioquímicas. Estudos do controle genético da tolerância ao $\mathrm{Al}$ tornam-se extremamente importantes para programas de melhoramento que visam a produzir cultivares economicamente importantes em solos ácidos. Em adição, há a necessidade de se clonar genes de tolerância ao Al e identificar as proteínas que eles codificam. A identificação de marcadores moleculares ligados a genes de tolerância ao $\mathrm{Al}$ auxiliará nos programas de melhoramento uma vez que poderão contribuir para incrementar a eficiência do processo através de seleção assistida. Devido à complexidade da fitotoxicidade do $\mathrm{Al}$ e dos mecanismos de tolerância apresentados pelas plantas, bem como da interação com diferentes fatores do solo, esse problema, além de ser um desafio para a biologia molecular vegetal, tem que ser alvo de cooperação entre cientistas de solo, melhoristas de plantas, bioquímicos vegetais e talvez patologistas. Sem dúvida, uma abordagem multi-disciplinar é essencial para a elucidação dos vários aspectos envolvidos na fitotoxicidade do $\mathrm{Al}$ e para a obtenção de cultivares tolerantes ao mesmo, permitindo um melhor aproveitamento dos solos ácidos ricos em $\mathrm{Al}$ que representam um sério problema no sul do Brasil.

\section{REFERÊNCIAS BIBLIOGRÁFICAS}

AHN, S., ANDERSON, J.A., SORRELLS, M.A., $\boldsymbol{e t}$ al. Homeologous relationship of rice, wheat and maize chromosomes. Molecular and General Genetics, Berlin, v.241, p.483-490, 1993.

ANIOL, A. Genetics of tolerance to aluminum in wheat (Triticum aestivum L. Thell). Plant and Soil, Netherlands, v.123, p.223-227, 1990.

ANIOL, A., GUSTAFSON, J.P. Chromosome location of genes controlling aluminum tolerance in wheat, rye, and triticale. Canadian Journal of Genetics and Cytology, Ottawa, v.26, p.701-705, 1984.

ANIOL, A.M. Physiological aspects of aluminium tolerance associated with the long arm of chromosome 2D of the wheat (Triticum aestivum L.) genome. Theoretical and Applied Genetics, Berlin, v.91, p.510-516, 1995.

BARCELÓ, J., POSCHENRIEDER, Ch. Plant water relations as effected by heavy metal stress: a review. Journal of Plant Nutrition, New York, v.13, p.1-37, 1990.

BARCELÓ, J., POSCHENRIEDER, Ch; VÁZQUEZ, M.D., et al. Aluminum phytotoxicity. Fertilizer Research, The Hague, v.43, p.217-223, 1996

BENNET, R.J., BREEN, C.M. The aluminium signal: new dimensions to mechanisms of aluminium tolerance. Plant and Soil, Netherlands, v.134, p.153-166, 1991.

BENNETZEN, J.L., FREELING, M. Grasses as a single genetic system: genome composition, colinearity and compatibility. Trends in Genetics, Amsterdam, v.9, p.259-261, 1993.

BOHNEN, H. Acidez e calagem. In: GIANELLO, C., BISSANI, C.A., TEDESCO, M.J. (eds.) Princípios de fertilidade de solo. Porto Alegre : Dep. de Solos. Fac. de Agronomia. UFRGS, 1995. p.51-76.

CAMBRAIA, J., CAMBRAIA, M.C. Avaliação de híbridos de milho quanto à tolerância ao alumínio, em solução nutritiva. Revista Ceres, Viçosa, v.42, p.297-307, 1995.

Ciência Rural, v. 31, n. 3, 2001. 
CLARKSON, D.T. The effect of aluminium and some other trivalent metal cations on cell division in the root apices of Allium cepa. Annals of Botany, London, v.107, p.315-321, 1965.

DALE, J.E., SUTCLIFFE, J.F. Water relations of plant cells. In: STEWARD, F.C., SUTCLIFFE, J.F., DALE, J.E. (eds.) Plant physiology, a treatise. V.9: Water and solutes in plants. Orlando: Academic, 1986.: p.1-48.

DEGENHARDT, J., LARSEN, P.B., HOWELL, S.H., $\boldsymbol{e} \boldsymbol{t}$ al. Aluminum resistance in the Arabidopsis mutant alr-104 is caused by an aluminum-induced increase in rhizosphere $\mathrm{pH}$. Plant Physiology, Minneapolis, v.117, p.19-27, 1998.

DELHAIZE, E., RYAN P.R. Aluminum toxicity and tolerance in plants. Plant Physiology, Minneapolis, v.107, p.315-321, 1995.

DELHAIZE, E., CRAIG, S., BEATON, C.D., et al. Aluminum tolerance in wheat (Triticum aestivum L.). I. Uptake and distribution of aluminum in root apices. Plant Physiology, Minneapolis, v.103, p.685-693, 1993a.

DELHAIZE, E., RYAN, P.R., RANDALL, P.J. Aluminum tolerance in wheat (Triticum aestivum L.). II. Aluminumstimulated excretion of malic acid from root apices. Plant Physiology, Minneapolis, v.103, p.695-702, 1993b.

DEVO, K.M., MILlAN, T., GALE, M.D. Comparative RFLP maps of the homeologous group-2 chromosomes of wheat, rye and barley. Theoretical and Applied Genetics, Berlin, v.85, p.784-792, 1993.

DODGE, C.S., HIATT, A.J. Relationship of $\mathrm{pH}$ to ion uptake imbalance by varieties of wheat (Triticum vulgare). Agronomy Journal, Madison, v.64, p.476-481, 1992.

DORNELLES, A.L.C., CARVALHO, F.I.F., FEDERIZZI, L.C., et al. Avaliação de genótipos de trigo hexaplóide quanto a tolerância ao alumínio. Ciência Rural, Santa Maria, v.26, p.19-22, 1996.

DORNELLES, A.L.C., CARVALHO, F.I.F., FEDERIZZI, L.C. et al. Avaliação simultânea para tolerância ao alumínio e sensibilidade ao ácido giberélico em trigo hexaplóide. Pesquisa Agropecuária Brasileira, Brasília, v.32, p.893896, 1997.

FENG MA, J., ZENG, S.J., FENG LI, X., et al. A rapid hydroponic screening for aluminium tolerance in barley. Plant and Soil, Netherlands, v.191, p.133-137, 1997.

FLEMING, A.L. Ammonium uptake by wheat varieties differing in Al tolerance. Agronomy Journal, Madison, v.75, p.726$730,1983$.

FOY, C.D. Physiological effects of hydrogen, aluminum and manganese toxicities in acid soil. In: ADAMS, F. (ed.). Soil acidity and liming. Madison: ASA-CSSA-SSSA, 1984. n.12, p.57-97. (Agron. Monogr.)

FOY, C.D., FLEMING, A.L. Crop tolerance to sub-optimal land conditions. Madison : ASA Meet., Houston, 1976. The physiology of plant tolerance to excess available aluminum and manganese in acid soils: p.301-328.

FOY, C.D., BURNS, G.R., BROWN, J.C., et al. Differential aluminum tolerance of two wheat varieties associated with plant-induced $\mathrm{pH}$ changes around their roots. S oil Science of America Proceeding, Madison, v.29, p.64-67, 1965.
FOY, C.D., CHANEL, R.L., WRITE, M.C. The physiology of metal toxicity in plants. Annual Review Plant Physiology, Bethesda, v.29, p.511-566, 1978.

FOY, C.D., FLEMING, A.L., BURNS, G.R., et al Characterization of differential aluminum tolerance among varieties of wheat and barley. Soil Science of America Proceeding, Madison, v.31, p.513-521, 1967.

GALLEGO, F.J., BENITO, C. Genetic control of aluminium tolerance in rye (Secale cereale L.). Theoretical and Applied Genetics, Berlin, v.92, p.688-695, 1997.

GARCIA, O.K., SILVA, W.J. Análise genética da tolerância ao alumínio em milho. Ciência e Cultura, São Paulo, v.31, $585 \mathrm{p}, 1979$.

HANG, A. Molecular aspects of aluminum toxicity. CRC Critical Reviews in Plant Sciences, Boca Raton, v.1, p.345373,1984

HANSON, J.B. The functions of calcium in plant nutrition. In: TINKER, P.B., LAUCHLI, A. (eds.) Advances in plant nutrition. New York : Praeger Scientific. 1984. V. 1, p.149208 .

HORST, Z.J., ASHER, C.J., CARMAK, L., et al. Short-term responses of soybean roots to aluminum. In: WRIGHT, R.J., BALIGAR, V.C., MURRAMANN, R.P. (eds.) Plant-soil interactions at low pH. Dordrecht : The Netherlands: Kluwer, 1991. p.733-739.

HUANG, J.W., GRUNES, D.L., KOCHIAN, L.V. Aluminum effects on the kinetics of calcium uptake into cells of the wheat root apex. Planta, Heidelberg, v.188, p.414-421, 1992.

HUE, N.V., CRADDOCK, G.R., ADAMS, F. Effect of organic acids on aluminum toxicity in subsoils. Soil Science of America Journal, Madison, v.50, p.28-34, 1986.

JONES, D.L., KOCHIAN, L.V. Aluminum inhibition of the 1,4,5-triphosphate signal transduction pathway in wheat roots: a role in aluminum toxicity? Plant Cell, Baltimore, v.7, p.1913-1922, 1995

JONES, U.S. Fertilizers \& soil fertility. Reston : Reston. 1979. $368 \mathrm{p}$.

KAUSS, H. Some aspects of calcium-dependent regulation in plant metabolism. Annual Review of Plant Physiology, Bethesda, v.38. p.47-72, 1987.

KAUSS, H. Role of the plasma membrane in host-pathogen interaction. In: LARSSON, C., MOLLER, I.M. (eds.) The plant plasma membrane, structure, function and molecular biology. Berlin : Springer-Verlag, 1990. p.320350 .

KERRIDGE, P.C., KRONSTADE, W.E. Evidence of genetic resistance to aluminium toxicity in wheat (Triticum aestivum vill. Horst.). Agronomy Journal, Madison, v.60, p.710-711, 1968 .

KHATIWADA, S.P., SENADHIRA, D., CARPENA, A.L., $\boldsymbol{e}$ t $\boldsymbol{a l}$. Variability and genetics of tolerance for aluminum toxicity in rice (Oriza sativa L.). Theoretical and Applied Genetics, Berlin, v.93, p.738-744, 1996.

KINRAIDE, T.B. Identity of the rhizotoxic aluminum species Plant and Soil, Netherlands, v.134, p.167-178, 1991. 
KINRAIDE, T.B., PARKER, D.R. Non-phytotoxicity of the aluminum sulfate ion, $\mathrm{AlSO}_{4}{ }^{+}$. Physiologia Plantarum, Copenhagen, v.71, p.207-212, 1987.

KINRAIDE, T.B., RYAN, P.R., KOCHIAN, L.V., et al. Interactive effects of $\mathrm{Al}^{3+}, \mathrm{H}^{+}$and other cations on root elongation considered in terms of cell-surface electrical potential. Plant Physiology, Minneapolis, v.99, p.1461$1468,1992$.

LAGOS, M.B., FERNANDES, M.I.M., CAMARGO, C.E.O., $\boldsymbol{e}$ al. Genetics and monosomic analysis of aluminum tolerance in wheat (Triticum aestivum L.). Revista Brasileira de Genética, Ribeirão Preto, v.14, p.1011-1020, 1991.

LAZOF, D.B., GOLDSMITH, J.G., RUFTY, T.M., et al. Rapid uptake of aluminum into cells of intact soybean root tips. A microanalytical study using secondary ion mass spectromatry. Plant Physiology, Minneapolis, v.106, p.1107-1114, 1994.

LLUGANY M., MASSOT, N., WISSEMEIER, A., et al. Differences in aluminium tolerance between maize varieties as assessed by callose formation and root elongation. Zeitschrift fur Pflanzenernährung und Bodenkunde, Weinheim, v.157, p.447-451, 1994.

MAGNAVACA, R., GRAMINER, C.D., CLARK, R.B Inheritance of aluminum tolerance in maize. In: GABEIMAN, H.W., LOUGNMAM, B.C. (eds.). Genetic aspects of plant mineral nutrition. Dordrecht Netherlands: Martinus Nijhoff. 1987. p.201-212.

MARSCHNER, H. Mechanisms of adaptation of plants to acid soils. In: WRIGHT, R.J., BALIGAR, V.C., MURRMANN, R.P. (eds.). Plant-soil interactions at low pH. Kluwer, Amsterdam : Netherlands, 1991. p.683-702.

MARTELL, A.E., MOTEKAITIS, R.J. Coordination chemistry and specification of $\mathrm{Al}(\mathrm{III})$ in aqueous solution. In: LEWIS, T.E. (ed.) Environmental chemistry and toxicology of aluminum. Chelsea, MI : Lewis, 1989. p.3-17.

MARTIN, R.B. Bioinorganic chemistry of aluminum. In SIGEL, H., SIGEL, A. (eds.). Metal ions in biological systems, v.24, Aluminum and its role in biology. New York : Marcel Dekker, 1988. p.1-57.

MATSUMOTO, H., HIRASAWA, F., TORIKAI, H., et $\boldsymbol{a}$. Localization of absorbed aluminium in pea root and its binding to nuclei acid. Plant Cell Physiology, Kyoto, v.17, p.627-631, 1976

MINELLA, E., SORRELLS, M.E. Inheritance and chromosome location of Alp, a gene controlling aluminum tolerance in "Dayton" barley. Plant Breeding, Berlin, v.116, p.465-469, 1997.

MIYASAKA, S.C., KOCHIAN, V.V., SHAFF, J.E., et al. Mechanisms of aluminum tolerance in wheat. An investigation of genotypic differences in rhizosphere $\mathrm{pH}, \mathrm{K}^{+}$, and $\mathrm{H}^{+}$transport, and root-cell membrane potencials. Plant Physiology, Minneapolis, v.91, p.1188-1196, 1989.

MIYASADA, S.C., BUTA, J.G., HOWELL, R.K., $\boldsymbol{e} t \boldsymbol{a l}$. Mechanisms of aluminum tolerance in snapbeans: root exudation of citric acid. P lant Physiology, Minneapolis, v.96, p.737-743, 1991

MOON, H.D., OTTOBONI, L.M.M., SOUZA, A.P., et al.
Somaclonal variation-induced aluminium-sensitive mutant from an aluminium-tolerant maize inbred line. Plant Cell Reports, Berlin, v.16, p.686-691, 1997.

MORIMURA, S., TAKAHASHI, E., MATSUMOTO, H Association of aluminium with nuclei and inhibition of cell division in onion (Allium cepa) roots. Zeitschrift fur Pflanzenphysiologie, Stuttgart, v.88, p.395-401, 1978.

MOUSTAKAS, M., OUZOUNIDOU, G., LANNOYE, R. Rapid screening for aluminum tolerance in cereals by use the chlorophyll fluorescence test. Plant Breeding, Berlin, v.111, p.343-346, 1993.

MUGWIRA, L.M., ELGAWAHRY, S.M., PATEL, S.U. Aluminum tolerance in triticale, wheat and rye as measured by root growth characteristics and aluminum concentration. Plant and Soil, Netherlands, v.50, p.681-690, 1978.

OLMOS, J.I.L., CAMARGO, M.N. Ocorrência de alumínio tóxico nos solos do Brasil, sua caracterização e distribuição. Ciência e Cultura, São Paulo, v.28, n.2, p.171-180, 1975.

PARKER, D.R., BERTSCH, P.M. Formation of the " $\mathrm{Al}_{13}$ " tridecameric polycation under diverse synthesis conditions. Environmental Science Technology, Easton, v.26: 914-921, 1992.

PELLET, D.M., GRUNES, D.L., KOCHIAN, L.V. Organic acid exudation as na aluminum tolerance mechanism in maize (Zea mays L.). Planta, Heidelberg, v.196, p.788-795, 1994.

POLLE, E., KONZAC, C.F., KITTRICK, J.A. Visual detection of aluminum tolerance levels in wheat by hematoxylin staining of seedling roots. Crop Science, Madison, v.18, p. $823-827,1978$.

PRIOLI, A.J. Análise genética da tolerância a toxidez do alumínio em milho (Zea mays L.). Campinas - SP, 1987. Tese (Doutorado em Genética) - Universidade Estadual de Campinas, 1987

PRIOLI, S.M.A.P., SILVA, J.C., GALVÃO, J.D., et al. Seleção da tolerância à toxidez de alumínio em milho (Zea mays $\mathrm{L}$.) Revista Ceres, Viçosa, v.32, p.441-451, 1985.

RAO, I.M., ZEIGLER, R.S., VERA, R., et al. Selection and breeding for acid-soil tolerance in crop. BioScience, Washington, v.43, n.7, p.454-465, 1993.

REID, D.A. Genetic control of reaction to aluminum in winter barley. In: NILAN, R.A. (ed.). Barley genetics II. Proc. $2^{\text {nd }}$ Int. Barley Genet. Symp., Pullman, WA. USA: Washington State University, 1969. p.409-413.

RENGEL, Z. Role of calcium in aluminium toxicity. The New Phytologist, Cambridge, v.121, p.499-513, 1992.

RHUE, R.D., GROGAN, C.D., STOCKMEYER, E.W., et al. Genetic control of aluminum tolerance in corn. Crop Science, Madison, v.18, p.1063-1067, 1978.

RYAN, P.R., KOCHIAN, L.V. Interaction between aluminum toxicity and calcium uptake at the root apex in near-isogenic lines of wheat (Triticum aestivum) differing in aluminum tolerance. Plant Physiology, Minneapolis, v.102, p.975-982, 1993. 
RYAN, P.R., DELHAIZE, E., RANDALL, P.J. Malate efflux from root apices: evidence for a general mechanism of $\mathrm{Al}$ tolerance in wheat. Australian Journal of Plant Physiology, Melbourne, v.22, p.531-536, 1995.

RYAN, P.R., DiTOMASO, J.M., KOCHIAN, L.V. Aluminum toxicity in roots: an investigation of spatial sensitivity and the role of the root cap. Journal Experimental Botany, Oxford, v.44, p.437-446, 1993

RYAN, P.R., KINRAIDE, T.B., KOCHIAN, L.V. $\mathrm{Al}^{3+}-\mathrm{Ca}^{2+}$ interactions in aluminum rhizotoxicity. I. Inhibition of root growth is not caused by reduction of calcium uptake. Planta, Heidelberg, v.192, p.98-103, 1994.

RYAN, P.R., REID, R.J., SMITH, F.A. Direct evaluation of the $\mathrm{Ca}^{2+}$-displacement hypothesis for $\mathrm{Al}$ toxicity. Plant Physiology, Minneapolis, v.113, p.1351-1357, 1997.

SAGHAI-MAROOF, M.A., SOLIMAN, K.M., JORGENSEN, R.A., et al. Analysis of the barley and rice genomes by comparative RFLP linkage mapping. Theoretical and Applied Genetics, Berlin, v.92, p.541-551, 1996.

SHERMAN, J.D., FENWICK, A.L., NAMUTH, D.M., et al. A barley RFLP: alignment of three barley maps and comparisons to gramineae species. Theoretical and Applied Genetics, Berlin, v.91, p.681-690, 1995.

SIBOV, S.T., GASPAR, M., SILVA, M.J., et al. Two genes control aluminum tolerance in maize: Genetic and molecular mapping analyses. Genome, Ottawa, v.42, p.1-8, 1999.

SPEHAR, C.R., GALWEY, N.W. Diallel analysis for aluminium tolerance in tropical soybeans [Glycine $\max (\mathrm{L}$.$) Merriel].$ Theoretical and Applied Genetics, Berlin, v.57, p.161-170, 1996.

ST ØLEN, O., ANDERSEN, S. Inheritance of tolerance to low soil pH in barley. Hereditas, Lund, v.88, p.101-105, 1978.
TAKAGI, H., NAMAI, H., MURAKAMI, K. Evaluation of the hematoxylin staining method for detecting wheat tolerance to aluminum. Japanese Journal Breeding, Tokyo, v.31, p.152160,1981

TAYLOR, G.J. The physiology of aluminum tolerance in higher plants. Communication in Soil Science and Plant Analysis, New York, v.19, p.1179-1194, 1988.

TAYLOR, G.J. Current views of the aluminum stress response: the physiological basis of tolerance. Current Topics in Plant Biochemistry Physiology, Missouri, v.10, p.57-93, 1991.

TEPPER, H.B., YANG, C.S., SCHAEDLE, M. Effect of aluminum on growth of root tips of honey locust and loblolly pine. Environmental and Experimental Botany, Elmsford, v.29, p.165-173, 1989.

TICE, K.R., PARKER, D.R., DeMASON, D.A. Operationally defined apoplastic and symplastic aluminum fractions in root tips of aluminum-intoxicated wheat. Plant Physiology, Minneapolis, v.100, p.309-318, 1992.

WISSEMEIER, A.H., DIENING, A., HERGENRÖDER, A., et al. Callose formation as parameter for assessing genotypical plant tolerance of aluminium and manganese. Plant and Soil, Netherlands, v.146, p.67-75, 1992.

WRIGHT, R.J. Soil aluminum toxicity and plant growth Communications in Soil Science and Plant Analysis, New York, v.20, p.1479-1497, 1989.

ZHANG, G., TAYLOR, G.J. Effects of biological inhibitors on kinetics of aluminum uptake by excised roots and purified cell wall material of aluminum-tolerant and aluminumsensitive cultivars of Triticum aestivum L. Journal of Plant Physiology, Stuttgart, v.138, p.533-539, 1991.

ZHAO, X.J., SUCOFF, E., STADELMANN, E.J. $\mathrm{Al}^{3+}$ and $\mathrm{Ca}^{2+}$ alteration of membrane permeability of Quercus rubre root cortex cells. Plant Physiology, Minneapolis, v.83, p.159$162,1987$.

Ciência Rural, v. 31, n. 3, 2001. 